\title{
Family Support as a Moderator of the Relationship Between Loneliness and Suicide Risk in College Students: Having a Supportive Family Matters!
}

\author{
Edward C. Chang', Olivia D. Chang ${ }^{2}$, Tamás Martos ${ }^{3}$, Viola Sallay ${ }^{3}$, \\ Jerin Lee', Kayla R. Stam', Casey N.-H. Batterbee', and Tina Yu
}

\begin{abstract}
In this study, we examined loneliness and family support as predictors of suicide risk (viz., depressive symptoms and suicide ideation) in college students. The sample was comprised of 456 Hungarian college students. Results of conducting hierarchical regression analyses, controlling for sex and age, indicated that the inclusion of family support provided further incremental validity in predicting both depressive symptoms and suicide ideation, beyond the variance accounted for by loneliness. Moreover, consistent with the notion that family support might buffer the negative effects of loneliness on suicide risk, evidence for a significant Loneliness $\times$ Family Support interaction effect in predicting both indices of suicide risk was found. Thus, beyond the role of loneliness in predicting suicide risk in college students, the present findings are the first to show how family support both additively and interactively represents a positive psychological resource that should be considered in understanding suicide risk among students.
\end{abstract}

\section{Keywords}

Loneliness, family support, depression, suicide ideation, college students

Mental health concerns are a serious and growing problem in adult populations around the world (World Health Organization [WHO], 2013) including in college student populations (e.g., Zivin, Eisenberg, Gollust, \& Golberstein, 2009). Indeed, one of the most serious concerns faced by college students has been, and continues to be, that of suicide (Drum, Brownson, Denmark, \& Smith, 2009; Westefeld et al., 2006). Among college-aged adults, suicide has been found to be the second leading cause of death behind unintentional injury (e.g., fatal traffic accidents, accidental poisoning; Centers for Disease Control and Prevention, 2014). According to the model proposed by Bonner and Rich (1987), both distal (viz., depressive symptoms) and proximal (viz., suicidal behaviors) variables are believed to increase the risk of committing suicide in college students. Indeed, consistent with their framework, findings from numerous studies over the past three decades have consistently implicated depression and suicidal behaviors (e.g., suicide ideation) as important risk factors associated with suicide in college student populations (Smith et al., 2015; Westefeld \& Furr, 1987). In the present study, we examine predictors associated with suicide risk among college students from Hungary, a country that historically has had one of the highest rates of suicide worldwide from 1950 to 2009 (Värnik, 2012) and continues to have rates of suicide among young adults that are typically greater than those found in the United States (WHO, 2014).

\section{Loneliness as a Critical Factor Associated With Suicide Risk in College Students}

Given the seriousness of suicide and its prevalence in college student populations (Drum et al., 2009; Schwartz \& Friedman, 2009; Westefeld et al., 2006), it is not surprising that researchers have focused on identifying important predictors of suicide risk in college students. One variable that has been frequently associated with greater suicide risk in adult populations is loneliness. Loneliness is defined by feelings and thoughts of being isolated and disconnected from others (Russell, Peplau, \&

\footnotetext{
' Department of Psychology, University of Michigan, Ann Arbor, MI, USA

${ }^{2}$ Research in Action Academy ${ }^{\mathrm{TM}}$, Ann Arbor, MI, USA

${ }^{3}$ Department of Personality, Clinical and Health Psychology, University of Szeged, Szeged, Hungary

Corresponding Author:

Edward C. Chang, Department of Psychology, University of Michigan, 530 Church Street, Ann Arbor, MI 48109, USA.

Email: changec@umich.edu
} 
Cutrona, 1980). Studies on loneliness over the past 30 years have indicated that it is a reliable correlate and predictor of a wide range of negative psychological conditions including depression and suicide ideation (see Heinrich \& Gullone, 2006, for a review). For example, in an early study examining predictors of suicide risk in college students, Weber, Metha, and Nelsen (1997) found that loneliness, as measured by the revised UCLA Loneliness Scale (R-UCLA; Russell et al., 1980), was associated with greater hopelessness and greater suicide ideation. Indeed, Westefeld and Furr (1987) found that in $47 \%$ of the adults who indicated a history of suicide ideation, loneliness was the most frequently cited cause of suicide ideation.

\section{Is the Presence of Family Support a Protective Factor Associated With Suicide Risk?}

Beyond the importance of examining vulnerability factors that might be associated with suicide risk in college students, there has been a growing interest to consider protective factors that might also be associated with (reduced) suicide risk (Wingate et al., 2006). Indeed, according to the WHO (2014), the identification of protective factors associated with suicide risk might prove useful in global efforts to reduce and ultimately prevent suicide among adults. In that regard, we focus in the present study on one potentially important protective factor, namely, family support. We contend that family support, the perception that one's family is readily able and willing to support each other during times of difficulty (Julkunen \& Greenglass, 1989), operates as a protective factor in two specific ways. First, family support should lower a student's risk of suicide by providing them with social capital. According to Coleman (1988), social capital, as derived from central sources like one's family, involves key interpersonal relationships that serve as positive resources for individuals when engaged in goal-driven activity (e.g., parents offering their child support in dealing with academic problems). Indeed, findings from numerous studies based on college students have shown that social support represents a major positive resource that is positively associated with positive outcomes (e.g., life satisfaction and positive mood; Brannan, BiswasDiener, Mohr, Mortazavi, \& Stein, 2013; Mahmoud, Staten, Lennie, \& Hall, 2015) and negatively associated with negative outcomes including suicide risk (e.g., depressive symptoms and suicide ideation; Clum \& Febbraro, 1994; Hirsch \& Barton, 2011; MacGeorge, Samter, Feng, Gillihan, \& Graves, 2004). Second, family support should also buffer the harmful effects associated with negative variables such as loneliness on suicide risk among college students. That is, for example, among lonely students, we would expect to see lower levels of suicide risk among those with high, compared to low, family support. To date, a prediction model in which family support is examined, above and beyond loneliness, as both a unique and an interactive predictor of suicide risk in college students, has yet to be tested.

\section{Purpose of the Present Study}

Given these possibilities, we conducted the present study in a sample of college students to (1) examine the relations between loneliness, family support, and suicide risk (viz., depressive symptoms and suicide ideation); (2) determine whether the inclusion of family support adds further incremental validity to the prediction of suicide risk, above and beyond loneliness; and (3) determine whether there is a significant Loneliness $\times$ Family Support interaction effect in predicting suicide risk.

Consistent with past research findings, we expected to find loneliness to be positively associated with suicide risk (Bonner \& Rich, 1987; Muyan \& Chang, 2015), whereas we expected to find family support to be negatively associated with suicide risk (Clum \& Febbraro, 1994; Hirsch \& Barton, 2011). Relatedly, given that loneliness involves the perceived absence of interpersonal networks (Russell et al., 1980), we expected to find loneliness to be negatively associated with family support. Furthermore, as an important and positive social resource associated with psychological adjustment (e.g., Brannan et al., 2013; MacGeorge et al., 2004), we hypothesized that the presence of family support would add significant incremental validity to the prediction of suicide risk, even after accounting for variance attributed to loneliness. Relatedly, consistent with the notion that family support might also buffer or weaken the association between loneliness and suicide risk, we expected to find support for a significant Loneliness $\times$ Family Support interaction effect.

\section{Method \\ Participants}

This study consisted of 456 Hungarian college students (225 males and 231 females) from a large public university in Budapest, Hungary. Ages ranged from 18 to 35 years, with a mean age of 21.52 years (standard deviation $[S D]=2.17$ ). The majority of the students were juniors $(46.3 \%)$, followed by freshmen (20.2\%), sophomores (20.0\%), and seniors (13.6\%).

\section{Measures}

Loneliness. To assess for loneliness, we used the R-UCLA (Russell et al., 1980). The scale consists of 20 items, half of which describe nonlonely thoughts (e.g., "There are people I feel close to"), while the other half characterizes feelings of loneliness (e.g., "I feel isolated from others"). Respondents are asked to rate the statements on the frequency to which they experience these feelings using a 4-point Likert-type scale, ranging from 1 (never) to 4 (often). We used an adapted Hungarian version of the R-UCLA in the present study (Csóka, Szabó, Sáfrány, Rochlitz, \& Bódizs, 2007). In the present sample, internal reliability for the R-UCLA was .93. Higher scores on the R-UCLA indicate greater levels of loneliness.

Family support. To assess for family support, we used the Family Support Scale (FSS; Julkunen \& Greenglass, 1989). The FSS is 
a 12-item self-report measure that assesses for family support (e.g., "My family supports me in all my efforts"). Respondents are asked to indicate the extent to which they agree with each item using a 5-point Likert-type scale, ranging from 1 (strongly disagree) to 5 (strongly agree). We used an adapted Hungarian version of the FSS in the present study. However, given our focus on college students and our desire to limit translation problems, items that assessed for the lack of family support ( 5 items) or family support in managing chronic illness (2 items) were not included. This resulted in a shortened 5-item version of the FSS that was used in the present study. The Hungarian translation was achieved following established guidelines for cross-cultural translation of instruments (Brislin, 1980). In the present sample, internal reliability for the FSS was .88. In general, higher scores on the FSS indicate greater perceived family support.

Suicide risk. To assess for suicide risk, we assessed for both depressive symptoms and suicide ideation. For depressive symptoms, we used the Beck Depression Inventory (BDI; Beck, Ward, Mendelson, Mock, \& Erbaugh, 1961). The BDI is a commonly used 21-item measure that assesses for depressive symptomatology (e.g., "I am so sad or unhappy that I can't stand it"). Respondents are asked to rate the extent to which they have experienced specific depressive symptoms in the past week, across a 4-point Likert-type scale (for example, $0=I$ do not feel sad to $3=$ I am so sad or unhappy that I can't stand it). We used an adapted Hungarian version of the BDI in the present study (Perczel Forintos, Kiss, \& Ajtay, 2007). In the present sample, internal reliability for the BDI was .92. Higher scores on the BDI indicate greater depressive symptomatology.

For suicide ideation, we used the Frequency of Suicidal Ideation Inventory (FSII; Chang \& Chang, 2016). The FSII is a 5-item scale that assesses for the frequency of suicide ideation over the past 12 months (e.g., "Over the past 12 months, how often have you thought about killing yourself?"). Respondents are asked to indicate how frequently they have entertained suicidal thoughts over the past year using a 5-point Likerttype scale, ranging from 1 (never) to 5 (almost every day). We used an adapted Hungarian version of the FSII (Chang et al., 2017) in the present study. In the present sample, internal reliability for the FSII was .94. Higher scores on the FSII indicate greater suicide ideation frequency.

\section{Procedure}

Approval for this study was obtained from the institutional review board at the university where the study was conducted prior to data collection. Participants were solicited from upper level psychology courses and received extra course credit upon completion of the survey.

\section{Results}

Given the focus of the present study, we controlled for sex and age in all of our analyses. Correlations, means, and $S D$ s for all
Table I. Partial Correlations Between Measures of Loneliness, Family Support, Depressive Symptoms, and Suicide Ideation in College Students, Controlling for Age and Sex.

\begin{tabular}{lcccc}
\hline Measures & 1 & 2 & 3 & 4 \\
\hline I. R-UCLA & - & & & \\
2. FSS & $-.54^{* * * *}$ & - & & \\
3. BDI & $.69 * * *$ & $-.44^{* * * *}$ & - & \\
4. FSII & $.59 * * *$ & $-.42^{* * *}$ & $.66^{* * *}$ & - \\
M & 35.57 & 19.29 & 8.91 & 7.33 \\
SD & 11.55 & 4.88 & 9.17 & 3.78 \\
\hline
\end{tabular}

Note. $N=456$. R-UCLA $=$ Revised UCLA Loneliness Scale; FSS = Family Support Scale; BDI = Beck Depression Inventory; FSII = Frequency of Suicidal Ideation Inventory; $S D=$ standard deviation. $* * * p<.001$.

study measures are presented in Table 1. As expected, loneliness was positively correlated with both depressive symptoms $(r=.69, p<.001)$ and suicide ideation $(r=.59, p<.001)$. Likewise, family support was negatively correlated with both depressive symptoms $(r=-.44, p<.001)$ and suicide ideation $(r=-.42, p<.001)$. Finally, loneliness and family support were found to be negatively associated with each other $(r=$ $-.54, p<.001)$.

\section{Examining Loneliness and Family Support as Predictors of Suicide Risk in College Students}

To examine whether family support would add incremental validity, beyond loneliness, in predicting suicide risk in college students, we conducted a set of hierarchical regression analyses. We controlled for age and sex in Step 1. Loneliness was entered in Step 2, followed by family support in Step 3. Finally, we entered the multiplicative Loneliness $\times$ Family Support term in Step 4 to determine whether family support might buffer the association found between loneliness and suicide risk. To determine whether any of the predictors accounted for a small, medium, or large amount of the variance in suicide risk, we used Cohen's (1977) convention for small $\left(f^{2}=.02\right)$, medium $\left(f^{2}=.15\right)$, and large effects $\left(f^{2}=\right.$ .35 ) as a general guide.

Results for predicting depressive symptoms and suicide ideation are presented in Table 2. As the table shows, control variables as a set was found to account for a small $\left(f^{2}=.03\right)$, but significant $3.0 \%$ of the variance in depressive symptoms. Within the predictor set, sex was the only significant predictor $\left(\beta=.15^{* *}, p<.01\right)$. When loneliness was entered, it was found to be a significant unique predictor $(\beta=.69 * * *, p<.001)$, accounting for a large $\left(f^{2}=.88\right) 46.8 \%$ of additional unique variance in depressive symptoms. Next, when family support was entered, it was found to be a significant unique predictor ( $\beta$ $\left.=-.09^{*}, p<.05\right)$, accounting for a small $\left(f^{2}=.01\right)$, but significant $0.6 \%$ of additional unique variance in depressive symptoms. Finally, when the Loneliness $\times$ Family Support term was entered, it was found to account for a small $\left(f^{2}=\right.$ .01 ), but significant $1.3 \%$ of additional unique variance in 
Table 2. Results of Hierarchical Regression Analyses Showing Amount of Variance in Depressive Symptoms and Suicide Ideation Accounted for by Loneliness and Family Support in College Students, After Controlling for Age and Sex.

\begin{tabular}{lllllll}
\hline Outcome & $\beta$ & $R^{2}$ & $\Delta R^{2}$ & $F$ & $P$ \\
\hline $\begin{array}{l}\text { Depressive symptoms } \\
\text { Step I: Demographics }\end{array}$ & & & & & & \\
$\quad$ Age & .08 & & & & & \\
$\quad$ Sex & $.15^{* *}$ & & & & & \\
$\quad$ Step 2: Loneliness & $.69^{* * *}$ & .49 & 0.47 & 418.40 & $<.001$ \\
Step 3: Family support & $-.09^{*}$ & .50 & 0.01 & 5.07 & $<.05$ \\
Step 4: Loneliness $\times$ Family & $-.37^{* * * *}$ & .51 & 0.01 & 12.39 & $<.001$ \\
$\quad$ Support & & & & & \\
Suicide ideation & & & & & \\
Step I: Demographics & & .01 & - & 1.83 & $n s$ \\
$\quad$ Age & .05 & & & & \\
$\quad$ Sex & .08 & & & & \\
Step 2: Loneliness & $.59^{* * *}$ & .35 & 0.34 & 239.44 & $<.001$ \\
Step 3: Family support & $-.14^{* *}$ & .36 & 0.01 & 10.06 & $<.01$ \\
Step 4: Loneliness $\times$ Family & $-.40^{* * *}$ & .38 & 0.02 & 11.53 & $\leq .001$ \\
$\quad$ Support & & & & & \\
\hline
\end{tabular}

Note. $N=456$.

$* p<.05 . * * p<.01 . * * * p \leq .001$.

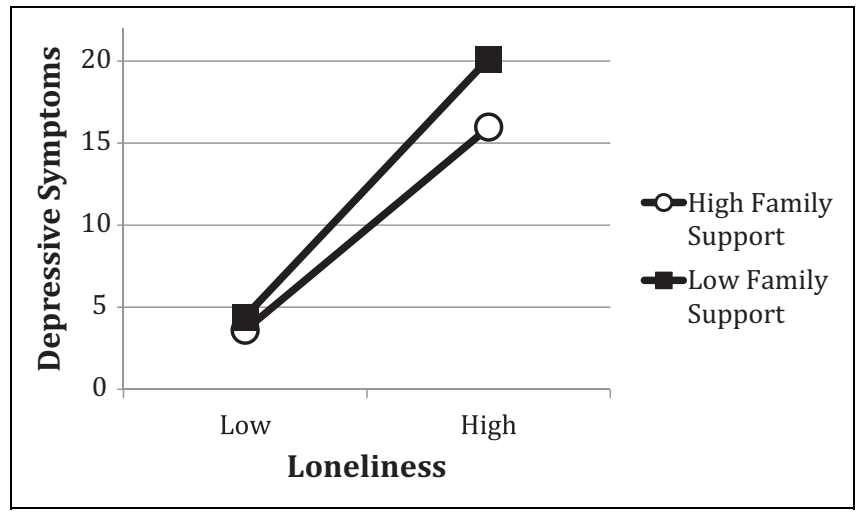

Figure I. Depressive symptoms at low versus high family support for nonlonely and lonely students.

depressive symptoms $\left(\beta=-.37^{* * *}, p<.001\right)$. The total model was found to account for a large $\left(f^{2}=1.05\right) 51.3 \%$ of the variance in depressive symptoms, $F(5,450)=94.95, p<.001$.

To visually inspect the manner in which loneliness and family support interacted with each other in predicting depressive symptoms, we plotted the regression of depressive symptoms on loneliness at low and high levels $( \pm 1 / 2 S D$ below and above the mean $[29.79,41.34]$, respectively) of low and high family support $( \pm 1 / 2 S D$ below and above the mean $[16.85,21.75]$, respectively), based on our initial regression results (see Figure 1). As the figure shows, the result of plotting this interaction offers some support for the notion that family support buffers the association between loneliness and depressive symptoms. Specifically, among lonely students, having high family support was associated with lower depressive symptoms compared to those with low family support.

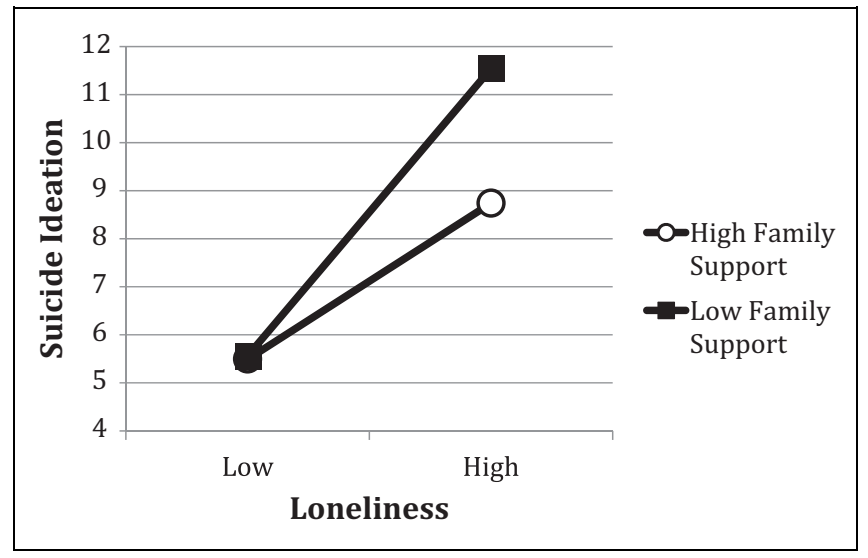

Figure 2. Suicide ideation at low versus high family support for nonlonely and lonely students.

In predicting suicide ideation, control variables as a set was not found to account for a significant amount of the variance in suicide ideation. However, when loneliness was entered, it was found to be a significant unique predictor $\left(\beta=.59^{* * *}, p<\right.$ $.001)$, accounting for a large $\left(f^{2}=.52\right) 34.4 \%$ of additional unique variance in suicide ideation. Next, when family support was entered, it was found to be a significant unique predictor ( $\beta$ $\left.=-.14^{* *}, p<.01\right)$, accounting for a small $\left(f^{2}=.01\right)$, but significant $1.4 \%$ of additional unique variance in suicide ideation. Finally, when the Loneliness $\times$ Family Support term was entered, it was found to account for a small $\left(f^{\mathcal{2}}=.02\right)$, but significant $1.6 \%$ of additional unique variance in suicide ideation $\left(\beta=-.40^{* * *}, p \leq .001\right)$. The total model was found to account for a large $\left(f^{2}=.62\right) 38.2 \%$ of the variance in suicide ideation, $F(5,450)=55.52, p<.001$.

Again, to visually inspect the manner in which loneliness and family support interacted with each other in predicting suicide ideation, we plotted the regression of suicide ideation on loneliness at low and high levels $\left( \pm^{1 / 2} S D\right.$ below and above the mean, respectively) of low and high family support $( \pm 1 / 2$ $S D$ below and above the mean, respectively), based on our initial regression results (see Figure 2). As the figure shows, the result of plotting this interaction again offers some support for the notion that family support buffers the association between loneliness and suicide ideation. Specifically, among lonely students, having high family support was associated with lower suicide ideation compared to those with low family support.

\section{Discussion}

One goal of the present study was to examine the relations between loneliness, family support, and suicide risk in college students. Consistent with past research findings pointing to loneliness as a critical concomitant of heightened suicide risk in adults (e.g., Bonner \& Rich, 1987; Muyan \& Chang, 2015), we found loneliness to be positively associated with both indices of suicide risk, namely, depressive symptoms and suicide ideation. Thus, these findings indicate that college 
students who feel isolated or disconnected from others are not only more likely to be dysphoric, but they are also more likely to harbor lethal thoughts involving self-harm. In contrast, consistent with the notion that support from the family represents a protective factor associated with suicide risk (e.g., Clum \& Febbraro, 1994; Hirsch \& Barton, 2011), family support was found to be negatively associated with both indices of suicide risk in the present study. That is, students with a supportive family were less likely to be dysphoric and less likely to harbor lethal self-harmful thoughts. Overall, these findings underscore a central point, namely, the importance of considering multiple factors that may be associated with suicide risk in adults (WHO, 2013, 2014).

Another important goal of the present study was to determine whether the addition of family support would add further incremental validity to the prediction of suicide risk in college students, even after controlling for the variance accounted for by loneliness. Consistent with expectations (e.g., Brannan et al., 2013; Julkunen \& Greenglass, 1989), we found that family support, after controlling for age and sex, added significant incremental validity to the prediction of both depressive symptoms and suicide ideation in students. Thus, although loneliness was found to be a robust predictor of both indices of suicide risk, the inclusion of family support provided a small but significant improvement in the prediction model. Moreover, consistent with the notion that levels of family support might moderate the association between loneliness and suicide risk, we found evidence for a significant Loneliness $\times$ Family Support interaction effect in predicting both depressive symptoms and suicide ideation. For both interactions, the plots indicated a weaker association between loneliness and suicide risk under high, compared to low, family support. Thus, our findings are consistent with the notion that family support represents an important protective factor associated with suicide risk in adults (WHO, 2014) and that it operates to buffer some of the potential negative effects of loneliness on depressive symptoms and suicide ideation in students.

Accordingly, these findings point to at least two important implications for developing strategies to potentially reduce heightened suicide risk in college students. First, and foremost, our regression findings underscore the general importance of working with students to reduce their experience of loneliness. For example, in a student experiencing heightened levels of dysphoria, suicide ideation, or both, it may prove useful for a counselor to focus on a number of specific processes to reduce loneliness, including increasing opportunities for social interaction with others, facilitating participation in a social support group on campus, providing social skills training, and addressing maladaptive social cognitions (Masi, Chen, Hawkley, \& Cacioppo, 2011). Second, our findings also indicate the importance of working with family members to foster and maintain a positive support system for the student. For example, parents might be trained to look for and identify early signs of suicide risk (e.g., dysphoria, suicide ideation) in students (Power et al., 2009) as well as signs strongly related to risk (e.g., social isolation). Thus, parents can serve as a first-line of defense in efforts to prevent or reduce the risk of suicide in students and to help students get the professional help needed when family support is simply not enough. Alternatively, our findings also point to the importance of having family counselors work with the family system to help promote and sustain positive and supportive environments for students that may be at risk of suicide. At the very least, when it comes to suicide risk in students, our findings indicate that having a supportive family environment matters.

Despite these important findings, it is also important to note a number of limitations to the present study. First, given that our findings on based on Hungarian college students, it would be useful to determine whether the present findings are generalizable to students from other cultural backgrounds (e.g., Chinese college students, American college students). Second, and relatedly, it would be important to determine whether different patterns emerge when studying high-risk students (e.g., students who are actively depressed or suicidal). Third, the present study focused on the role of perceived family support rather than objective family support (e.g., time spent with family members). Thus, it would be important in future studies to determine whether the presence of objective family support also matters in determining the association between loneliness and suicidal risk in college students. Lastly, it is important to note that beyond loneliness and family support, other factors should also be considered in future studies. For example, studies have shown that low future orientation (i.e., the belief that the future will not change for the better) is strongly associated with greater suicide risk in adult populations (e.g., Chang et al., 2013; Yu \& Chang, 2016).

\section{Concluding Thoughts}

In the present study, we examined the role of loneliness and family support as predictors of suicide risk (viz., depressive symptoms and suicide ideation) in college students. Beyond the robust role of loneliness as a predictor of suicide risk, we found that family support was uniquely predictive of suicide risk and also moderated the association found between loneliness and suicide risk. Overall, findings from the present study not only highlight the importance of considering the role that positive social resources, such as the family, might play in abating suicide risk, but they also highlight the value of studying the social conditions (e.g., high vs. low family support) under which the association between negative psychological variables and suicide risk might be weakened.

\section{Acknowledgment}

The first author would like to acknowledge Tae Myung-Sook and Chang Suk-Choon for their encouragement and support throughout this project.

\section{Declaration of Conflicting Interests}

The author(s) declared no potential conflict of interest with respect to the research, authorship, and/or publication of this article. 


\section{Funding}

The author(s) received no financial support for the research, authorship, and/or publication of this article.

\section{References}

Beck, A. T., Ward, C. H., Mendelson, M., Mock, J., \& Erbaugh, J. (1961). An inventory for measuring depression. Archives of General Psychiatry, 4, 561-571.

Bonner, R. L., \& Rich, A. R. (1987). Toward a predictive model of suicidal ideation and behavior: Some preliminary data in college students. Suicide and Life-Threatening Behavior, 17, 50-63.

Brannan, D., Biswas-Diener, R., Mohr, C. D., Mortazavi, S., \& Stein, N. (2013). Friends and family: A cross-cultural investigation of social support and subjective well-being among college students. The Journal of Positive Psychology, 8, 65-75.

Brislin, R. W. (1980). Translation and content analysis of oral and written material. In H. C. Triandis \& J. W. Berry (Eds.), Handbook of cross-cultural psychology (Vol. 1, pp. 389-444). Boston, MA: Allyn \& Bacon.

Centers for Disease Control and Prevention. (2014). Graphic representation of 10 leading causes of death in the United States in 2014, for both sexes. Leading causes of death reports, National and regional, 1999-2014. Retrieved from http://webappa.cdc.gov/sas web/ncipc/leadcaus10_us.html

Chang, E. C., \& Chang, O. D. (2016). Development of the frequency of suicidal ideation inventory: Evidence for the validity and reliability of a brief measure of suicidal ideation frequency in a college student population. Cognitive Therapy and Research, 40, 549-556.

Chang, E. C., Chang, O. D., Martos, T., Sallay, V., Najarian, A. S.-M., \& Lee, J. (2017). Validity of the Frequency of Suicidal Ideation Inventory in Hungarian adults. Death Studies, 41, 236-240.

Chang, E. C., Yu, E. A., Lee, J. Y., Hirsch, J. K., Kupfermann, Y., \& Kahle, E. R. (2013). An examination of optimism/pessimism and suicidal risk in primary care patients: Does belief in a changeable future make a difference? Cognitive Therapy and Research, 37, 1285-1293.

Clum, G. A., \& Febbraro, G. A. (1994). Stress, social support, and problem-solving appraisal/skills: Prediction of suicide severity within a college sample. Journal of Psychopathology and Behavioral Assessment, 16, 69-83.

Cohen, J. (1977). Statistical power analysis for the behavioral sciences (rev. ed.). New York, NY: Academic Press.

Coleman, J. S. (1988). Social capital in the creation of human capital. American Journal of Sociology, 94, S95-S120.

Csóka, S., Szabó, G., Sáfrány, E., Rochlitz, R., \& Bódizs, R. (2007). Kísérlet a felnőttkori kötődés mérésére-A kapcsolati kérdőív (Relationship Scale Questionnaire) magyar változata. [An attempt to measure adult attachment-The Hungarian version of the Relationship Scale Questionnaire]. Pszichológia, 27, 333-355.

Drum, D. J., Brownson, C., Denmark, A. B., \& Smith, S. (2009). New data on the nature of suicidal crises in college students: Shifting the paradigm. Professional Psychology: Research and Practice, 40, $213-222$
Heinrich, L. M., \& Gullone, E. (2006). The clinical significance of loneliness: A literature review. Clinical Psychology Review, 26, 695-718.

Hirsch, J. K., \& Barton, A. L. (2011). Positive social support, negative social exchanges, and suicidal behavior in college students. Journal of American College Health, 59, 393-398.

Julkunen, J., \& Greenglass, E. R. (1989). Family support measure. Unpublished manuscript.

MacGeorge, E. L., Samter, W., Feng, B., Gillihan, S. J., \& Graves, A. R. (2004). Stress, social support, and health among college students after September 11, 2001. Journal of College Student Development, 45, 655-670.

Mahmoud, J. R., Staten, R., Lennie, T. A., \& Hall, L. A. (2015). The relationships of coping, negative thinking, life satisfaction, social support, and selected demographics with anxiety of young adult college students. Journal of Child and Adolescent Psychiatric Nursing, 28, 97-108.

Masi, C. M., Chen, H. Y., Hawkley, L. C., \& Cacioppo, J. T. (2011). A meta-analysis of interventions to reduce loneliness. Personality and Social Psychology Review, 15, 219-266.

Muyan, M., \& Chang, E. C. (2015). Perfectionism as a predictor of suicidal risk in Turkish college students: Does loneliness contribute to further risk? Cognitive Therapy and Research, 39, 776-784.

Perczel Forintos, D., Kiss, Z., \& Ajtay, G. (2007). Beck Depresszió Kérdőív [Beck Depression Inventory]. In D. Perczel Forintos, Z. Kiss, \& G. Ajtay (Eds.), Kérdöivek, becslöskálák a klinikai pszichológiában (pp. 40-43). Budapest, Hungary: Országos Pszichiátriai és Neurológiai Intézet.

Power, L., Morgan, S., Byrne, S., Boylan, C., Carthy, A., Crowley, S., ... Guerin, S. (2009). A pilot study evaluating a support programme for parents of young people with suicidal behaviour. Child and Adolescent Psychiatry and Mental Health, 3, 20.

Russell, D., Peplau, L. A., \& Cutrona, C. E. (1980). The revised UCLA Loneliness Scale: Concurrent and discriminant validity evidence. Journal of Personality and Social Psychology, 39, 472-480.

Schwartz, L. J., \& Friedman, H. A. (2009). College student suicide. Journal of College Student Psychotherapy, 23, 78-102.

Smith, S. S., Carter, J. S., Karczewski, S., Pivarunas, B., Suffoletto, S., \& Munin, A. (2015). Mediating effects of stress, weight-related issues, and depression on suicidality in college students. Journal of American College Health, 63, 1-12.

Värnik, P. (2012). Suicide in the world. International Journal of Environmental Research and Public Health, 9, 760-771.

Weber, B., Metha, A., \& Nelsen, E. (1997). Relationships among multiple suicide ideation risk factors in college students. Journal of College Student Psychotherapy, 11, 49-64.

Westefeld, J. S., Button, C., Haley, J. J., Kettmenn, J. J., MacConnell, J., Sandil, R., \& Tallman, B. (2006). College student suicide: A call to action. Death Studies, 30, 931-956.

Westefeld, J. S., \& Furr, S. R. (1987). Suicide and depression among college students. Professional Psychology: Research and Practice, 18, 119-123.

Wingate, L. R., Burns, A. B., Gordon, K. H., Perez, M., Walker, R. L., Williams, F. M., \& Joiner, T. (2006). Suicide and positive cognitions: Positive psychology applied to the understanding and treatment of suicidal behavior. In T. E. Ellis (Ed.), Cognition and 
suicide: Theory, research, and therapy (pp. 261-283). Washington, DC: American Psychological Association.

World Health Organization. (2013). Mental health action plan 20132020. Geneva, Switzerland: Author.

World Health Organization. (2014). Preventing suicide: A global imperative. Geneva, Switzerland: Author.
Yu, E. A., \& Chang, E. C. (2016). Optimism/pessimism and future orientation as predictors of suicidal ideation: Are there ethnic differences? Cultural Diversity and Ethnic Minority Psychology, 22, 572-579.

Zivin, K., Eisenberg, D., Gollust, S. E., \& Golberstein, E. (2009). Persistence of mental health problems and needs in college student populations. Journal of Affective Disorders, 117, 180-185. 